\title{
Seroprevalence and Associated Risk Factors of Brucellosis in Livestock and Residents of New Valley Governorate, Egypt
}

\author{
Mohamed Said Diab ${ }^{1 *}$, Sherif Abd Allah Zidan², Nermin Abdalla A. Hassan ${ }^{2}$, Haitham Elaadli ${ }^{3}$ and Ahmed \\ Mohamed Bayoumi ${ }^{2}$ \\ ${ }^{I}$ Department of Animal Hygiene and Zoonoses, Faculty of Veterinary Medicine, New Valley University, Egypt \\ ${ }^{2}$ Department of Animal Hygiene and Zoonoses, Faculty of Veterinary Medicine, University of Sadat City, Egypt \\ ${ }^{3}$ Department of Animal Hygiene and Zoonoses, Faculty of Veterinary Medicine, Alexandria University, Egypt \\ *Corresponding author’s E-mail: mohameddiab333@gmail.com; (DORCiD: 0000-0002-4878-1534
}

\begin{abstract}
Brucellosis is a worldwide zoonotic disease which is now considered endemic in most parts of Egypt. A crosssectional study was carried out from December 2018 to February 2020 to investigate the seroprevalence of brucellosis in humans and livestock residing in two regions located in New Valley Governorate, Egypt. A total of 1254 animals (673 cattle, 348 sheep, and 233 goats) and 523 human serum samples were examined for brucellosis using Rose Bengal test (RBT) and then randomly selected sera (15 from cattle, 7 from sheep, 3 from goats, and 45 from humans) were further analyzed by complement fixation test, enzyme-linked immunosorbent assay to compare and detect the sensitivity and specificity of RBT. The prevalence of brucellosis was $0 \%$ in cattle, sheep, and goats while it was $23.9 \%$ in humans using RBT. Concerning humans, there was a higher percentage of infection in EL Kharga (33.6\%). The prevalence of this infection was also at a higher level among individuals aged above 40 years (28.57\%). Furthermore, men (26.11\%) were more inclined to be inflicted, compared to women (22.5\%) with no significant difference. Considering the human occupation, abattoir workers were the most predominant group of people at risk $(33.3 \%)$, followed by farmers $(31.25 \%)$ and animal keepers $(20.6 \%)$ while the lowest prevalence was demonstrated in the housewives where the prevalence was $18.8 \%$. As a result, risk factors of the age range, locality, time of infection, contact with animals, and occupational groups could significantly affect the prevalence of human brucellosis in the New Valley Governorate. In conclusion, brucellosis is an alarming problem among residents of the New Valley Governorate. Thus, reducing the prevalence in humans and animals in the region of study may include restriction of the marketing the raw milk and enhancing public health awareness.
\end{abstract}

Keywords: Brucellosis, Cattle, Complement fixation test, ELISA, Human, Rose Bengal test, Sheep and goats.

\section{INTRODUCTION}

Brucellosis is one of the most common worldwide zoonotic diseases, which requires major economic considerations. The reason is that it can intervene in the normal daily activities of the inflicted infected patients leading to a serious impact on public health. It can also have a detrimental effect on animal production by decreasing the reproductive efficiency, milk yield, as well as the increase of abortion (Corbel, 2006). The etiological agents causing brucellosis belong to the genus Brucella, and the classical zoonotic type is Br. abortus, Br. melitensis, Br. suis, and Br. canis (Pappas and Memish, 2007; Godfroid, 2017).

Humans can be infected with brucellosis by contacting animals (i.e., secretion, carcasses, or ingestion) or by consuming their products, mainly unpasteurized dairy products (Aparicio, 2013). Human symptoms mainly include undulant fever, malaise, insomnia, arthralgia, sweating, fatigue, weight loss, headache, and joint pain also, some cases may have neurological complications, endocarditis and testicular or bone abscess formation (Acha and Szyfres, 2003; Corbel, 2006). Human brucellosis proved to be a serious occupational health hazard to livestock handlers particularly abattoir workers, butchers, and veterinarians in Egypt (Zakaria et al., 2018)

Brucellosis was first reported in Egypt in 1939, but now it is endemic (Refai, 2002; Eltholth et al., 2015). In 2007, the prevalence rates of brucellosis in livestock were significantly higher in Beni Suef than other regions of Egypt (Samaha, 2008). The disease has been predominantly detected in ruminants with varied prevalence and some regions of Egypt, such as New Valley province, reported no inflicted case of Brucellosis (Wareth et al., 2014; Eltholth et al., 2017).

Isolation of Brucella is considered as a gold standard and the most reliable method of diagnosis; however, it is difficult and time-consuming to perform with a great risk of infection for laboratory workers, which necessitates specific biosafety measures (Mathew et al., 2015). In this regard, a variety of serological tests, such as Rose Bengal Test (RBT), Complement Fixation Test (CFT), Enzyme-Linked Immunosorbent Assay (ELISA), tube agglutination test, and buffered acidified plate antigen test can be used for the recognition of Brucella specific antibodies (Fatima et al., 2016). The RBT 
is simple, good, rapid, and easy to perform and can be used as a herd screening test at remote places (Teng et al., 2017; Diab et al., 2018). Moreover, CFT and ELISA can be utilized as a confirmatory test for Brucella diagnosis (Ashraf et al., 2014). The combination of RBT and CFT can be suggested as the best method for the diagnosis of brucellosis (Chisi et al., 2017).

The current study aimed to provide the first report of the prevalence rate of brucellosis in cattle, sheep, goats, and humans residing in New Valley Governorate, Egypt, using RBT confirmed by CFT and ELISA.

\section{MATERIALS AND METHODS}

\section{Study area and period}

The study was carried out in New Valley Governorate from December 2018 to February 2020. The study population consisted of cattle, sheep, goats, and humans from two regions located in the New Valley Governorate to study the seroprevalence of brucellosis.

\section{Samples}

Animal samples

A total of 1254 serum samples of farm animals (i.e., 673 cattle, 348 sheep, and 233 goats) were collected from December 2018 to December 2019, and the full history of each animal, including sex, age, season, and locality, was recorded.

\section{Human samples}

A total of 523 human serum samples were collected from patients (males or females) with the age range of 10-70 years from New Valley Fever hospital and various clinic laboratories in New Valley Governorate from December 2018 to February 2020. Demographic information of participants (i.e., gender, age, locality, and time of infliction) was also documented in the current study.

\section{Sample collection and processing}

The samples in the present study included 5-7 ml of blood from the jugular vein of the investigated animals and the cephalic vein of human cases using sterile disposable syringes. Immediately after collection of the blood sample in a sterile glass tube, the blood was left to stand still for about 30 minutes and then centrifuged at 3000 rpm for 10 minutes to obtain non-haemolyzed clear serum using sterile Pasteur pipettes followed by keeping the samples in Eppendorf tubes and labeling the tubes. The separated serum was stored in a labeled tube at $-20{ }^{\circ} \mathrm{C}$ until serological examination. The number of serum samples examined from cattle, sheep, goats, and humans in two areas of New Valley Governorate are shown in table 1.

Table 1. Number of serum samples examined from cattle, sheep, goats, and humans in two areas of New Valley Governorate, Egypt

\begin{tabular}{|c|c|c|c|}
\hline Samples & El Kharga & EL Dakhla & Total \\
\hline Cattle & 484 & 189 & 673 \\
\hline Sheep & 252 & 96 & 348 \\
\hline Goat & 186 & 47 & 233 \\
\hline Total & 922 & 332 & 1254 \\
\hline Human & 327 & 196 & 523 \\
\hline
\end{tabular}

\section{Serological test}

\section{Rose Bengal Test}

All tested serum samples (i.e., 673 cattle, 348 sheep, 233 goats, and 523 humans) were examined using antigen stained with Rose Bengal and buffered to a low $\mathrm{pH}(3.65+0.05)$, the reagent was obtained from Veterinary Serum and Vaccine Research Institute (VSVRI), Abbassia, Cairo, Egypt. The test was performed simply by adding $25 \mu$ of both tested serum and the reagent were placed next to the plate and then mixed thoroughly using glass rode or toothpick, shaking the plate with an electric rocker for four minutes. Then the degree of agglutination was recorded. The results were considered positive if agglutination was detected and negative if no agglutination was found.

\section{Complement fixation test}

Randomly selected samples were retested for anti-Brucella antibodies with CFT. Components were obtained from VSVRI, Abbassia, Cairo, Egypt, and the CFT was performed at Brucella Unit in Central Laboratory Evaluation for Veterinary Biologics, Abbasia, Cairo, Egypt. The test was performed according to Alton et al. (1988).

\section{Enzyme linked immunosorbant assay}

The selected samples were randomly retested for anti-Brucella antibodies using ELISA. The cELISA was performed by using the ID Screen® Brucellosis Serum Indirect Multi-species (ID-Vet, France) and the Human Brucella 
IgM ELISA Test Kit (Diagnostic Automation /Cortez Diagnostics, USA.) for animal and human sera. The results were interpreted according to the instructions of the manufactures.

\section{Statistical analysis}

Data analysis was run using the Chi-square test. The P-value is the probability of the event occurring by chance if the null hypothesis is true. P-value less than 0.05 was considered statistically significant.

Sensitivity $=$ True Positives $($ TP $) /[$ True Positive $($ TP $)+$ False Negative $(F N)] \times 100$.

Specificity $=$ True Negatives $(\mathrm{TN}) /[$ True Negative $(\mathrm{TN})+$ False Positives $(\mathrm{FP})] \times 100$.

\section{Ethical approval}

All procedures in the current study, including human and animal sera collection, were in accordance with the Egyptian ethical standards of the national research committee. All human subjects gave their consent for the collection of the serum samples, with the agreement that any identifying details of the individuals should not be published.

\section{RESULTS}

The obtained results of RBT revealed no seroprevalence of brucellosis in cattle, sheep, and goats (Table 2). However, the seroprevalence of brucellosis by CFT and ELISA was reported 20\%, and $0 \%$ in cattle, respectively. No seroprevalence of brucellosis was observed in sheep and goats using both CFT and ELISA (Table 3).

As can be seen in table 4, the analysis of seroprevalence of brucellosis in humans using RBT was $23.9 \%$, while this rate was reported as $28.9 \%$ utilizing CFT and $31.1 \%$ employing ELISA (Table 5). As observed in table 6, the investigation of risk factors of age indicated that there was a significant relationship between human age and infection with Brucella $(\mathrm{p}<0.05)$. Accordingly, the high percentage of infection was found in the age group > 40 years $(28.57 \%)$ followed by the age group <40 years (i.e., $17.20 \%$ ). Regarding locality, there was a highly significant relationship between locality and infection with brucellosis in humans $(\mathrm{p}<0.05)$, the highest infection was recorded in EL Kharga $(33.6 \%)$ and the lowest was for EL Dakhla (7.7\%). Although gender showed no significant relationship with brucellosis in humans, the occurrence of brucellosis was higher in males $(26.11 \%)$ than females $(22.5 \%)$. The finding addressing the time of infliction demonstrated that the highest percentage of infection was for days with hot weather (33.63\%).

Concerning occupational factors, there was a significant relationship between contact with animals and infection, seroprevalence of brucellosis was higher in individuals at close contact with animals $(28.4 \%)$ than those non-contacts $(18.8 \%)$. Although there was no significance between the consumption of raw dairy products and infection, the raw milk consumers group (25.5\%) showed a higher prevalence of infection, compared to non-milk consumer groups (22.4\%). The highest seroprevalence was recorded in the abattoir workers $(33.3 \%)$ followed by farmers $(31.25 \%)$, and then Animal Keepers $(20.6 \%$ ), while the lowest prevalence was demonstrated in the housewives where the prevalence was $18.8 \%$. As tabulated in table 7, the sensitivity of RBT and ELISA concerning results of CFT in cattle, sheep, and goats was reported $0 \%$, while the specificity of both tests was $100 \%$. The sensitivity and specificity rates of RBT were respectively $76.92 \%$ and $100 \%$ for human participants, and the sensitivity and specificity rates of ELISA were estimated at $100 \%$ and $96.88 \%$, respectively.

Table 2. Seroprevalence of brucellosis in animals living in New Valley Governorate, Egypt from December 2018 to December 2019 using RBT.

\begin{tabular}{|c|c|c|c|}
\hline $\begin{array}{ll}\text { Farm animals } & \text { RBT } \\
\end{array}$ & No. of examined samples & No. of Positive samples & Percentage \\
\hline Cattle & 673 & 0.0 & 0.0 \\
\hline Sheep & 348 & 0.0 & 0.0 \\
\hline Goat & 233 & 0.0 & 0.0 \\
\hline Total & 1254 & 0.0 & 0.0 \\
\hline
\end{tabular}

Table 3. Seroprevalence of brucellosis in animals living in New Valley Governorate from December 2018 to December 2019 using CFT and ELISA.

\begin{tabular}{|c|c|c|c|c|c|}
\hline \multirow{2}{*}{ Farm animals } & \multirow{2}{*}{ No. of examined samples } & \multicolumn{2}{|c|}{ CFT } & \multicolumn{2}{|c|}{ ELISA } \\
\hline & & $+\mathrm{ve}$ & $\%$ & +ve & $\%$ \\
\hline Cattle & 15 & 3 & 20 & 0.0 & 0.0 \\
\hline Sheep & 7 & 0.0 & 0.0 & 0.0 & 0.0 \\
\hline Goat & 3 & 0.0 & 0.0 & 0.0 & 0.0 \\
\hline Total & 25 & 3 & 12 & 0.0 & 0.0 \\
\hline
\end{tabular}

CFT: Complement Fixation Test; ELISA: Enzyme-Linked Immunosorbent Assay 
Table 4. Seroprevalence of brucellosis in humans residing in New Valley Governorate, Egypt from December 2018 to February 2020 using RBT.

\begin{tabular}{lccc}
\hline RBT & Total (number) & +Ve (number) & Percentage \\
\hline Humans & 523 & 125 & $23.9 \%$ \\
\hline RBT: Rose Bengal test
\end{tabular}

Table 5. Seroprevalence of brucellosis by in humans residing in New Valley Governorate, Egypt from December 2018 to February 2020 using CFT and ELISA.

\begin{tabular}{lc|cc|cc}
\hline \multirow{2}{*}{$\begin{array}{c}\text { No. of examined } \\
\text { samples }\end{array}$} & \multicolumn{2}{|c|}{ CFT } & \multicolumn{2}{c}{ ELISA } \\
\cline { 3 - 6 } & +ve (Number) & Percentage & +ve (number) & Percentage \\
\hline Human & 45 & 13 & 28.9 & 14 & 31.1 \\
\hline
\end{tabular}

CFT: Complement Fixation Test; ELISA: Enzyme-Linked Immunosorbent Assay

Table 6. Prevalence of brucellosis using RBT in humans regarding different risk factors in New Valley Governorate, Egypt

\begin{tabular}{|c|c|c|c|c|c|c|}
\hline Spec & & & Human $(5$ & & & \\
\hline Risk fa & tors & Total no. & $\begin{array}{c}\text { Positive } \\
\text { no. }\end{array}$ & Percentage & Chi-square & P-value \\
\hline Age & $<40 \mathrm{Y}$ & 308 & 88 & 28.57 & $8.987 *$ & \\
\hline & $>40 \mathrm{Y}$ & 215 & 37 & 17.20 & $\begin{array}{c}\text { significant at } \\
\mathrm{p}<0.05\end{array}$ & 0.002719 \\
\hline & El Kharga & 327 & 110 & 33.6 & $45.498 *$ & \\
\hline Locality & El Dakhla & 196 & 15 & 7.7 & $\begin{array}{c}\text { significant at } \\
\mathrm{p}<0.05\end{array}$ & 0.00001 \\
\hline $\mathrm{C}_{0}$ & Male & 203 & 53 & 26.11 & $0.8892 *$ & 02457 \\
\hline Gender & Female & 320 & 72 & 22.5 & Non-significant at $\mathrm{p}>0.05$ & $0.345 /$ \\
\hline & Hot weather & 327 & 109 & 33.63 & $42.6856 *$ & \\
\hline Weather & Cold weather & 196 & 16 & 8.16 & $\begin{array}{c}\text { significant at } \\
\mathrm{p}<0.05\end{array}$ & 0.00001 \\
\hline Contact with & Yes & 278 & 79 & 28.4 & $6.6563^{*}$ & 0009 \\
\hline animals & No & 245 & 46 & 18.8 & significant at $\mathrm{p}<0.05$ & 0.00 \\
\hline consumption of & Yes & 255 & 65 & 25.5 & 0.6914 NS & $0=0$ \\
\hline Raw dairy products & No & 268 & 60 & 22.4 & Non-significant at $\mathrm{P}>0.05$ & 0.4 \\
\hline & Farmers & 160 & 50 & 31.25 & & \\
\hline Occungtion & Abattoir worker & 30 & 10 & 33.3 & $9.8809 *$ & 0019 \\
\hline 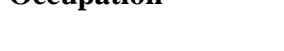 & Animal Keeper & 141 & 29 & 20.6 & significant at $\mathrm{p}<0.05$ & 0.011 \\
\hline & Housewives & 192 & 36 & 18.8 & & \\
\hline
\end{tabular}

Table 7. Comparison of the results of RBT and ELISA for the diagnosis of brucellosis in the investigated cattle, sheep, goats, and humans as well as detection of sensitivity and specificity of both tests.

\begin{tabular}{|c|c|c|c|c|}
\hline \multirow[b]{2}{*}{ Item } & \multicolumn{2}{|c|}{ RBT } & \multicolumn{2}{|c|}{ ELISA } \\
\hline & $\begin{array}{c}\text { Sensitivity } \\
(\%)\end{array}$ & $\begin{array}{c}\text { Specificity } \\
(\%)\end{array}$ & $\begin{array}{c}\text { Sensitivity } \\
(\%)\end{array}$ & $\begin{array}{c}\text { Specificity } \\
(\%)\end{array}$ \\
\hline Cattle & 0.0 & 100 & 0.0 & 100 \\
\hline Sheep & 0.0 & 100 & 0.0 & 100 \\
\hline Goat & 0.0 & 100 & 0.0 & 100 \\
\hline Human & 76.92 & 100 & 100 & 96.88 \\
\hline
\end{tabular}

RBT: Rose Bengal test, ELISA: Enzyme-Linked Immunosorbent Assay 
Brucellosis is one of the most common worldwide zoonotic diseases, which requires major economic considerations, especially in developing countries, including Egypt (Afifi et al., 2005). The diagnosis is mainly based on the serological tests since it is fast, easy to use, and available, compared to other culture techniques, that are not available in laboratories of endemic countries (Young et al., 2005). The combination of serological testing should be adopted to reduce the falsenegative number which contributes to the persistence of the herd problem and also to reduce the false positive number to avoid over condemnation by testing and slaughtering policy (Salem et al., 2016). Therefore, in the present study, RBT was used for the determination of brucellosis in livestock (i.e., cattle, sheep, and goats) as well as humans in the southwestern region of Egypt. As indicated in table 2, the overall prevalence rate of brucellosis in cattle, sheep, and goats was $0 \%$ using RBT.

Regarding cattle, the obtained results of the current study were in line with those obtained by Cadmus et al. (2006) and Nagi (2003) who respectively reported the seroprevalence rates of $0 \%$ and $0.70 \%$ among cattle. In contrast, (Musallam et al., 2015) and (Anka et al., 2013) reported higher rates of seroprevalence for cattle (i.e., 18.1\% and 21.8\%, respectively). Considering sheep, the findings of the current study yield support the results of a study conducted by Samaha (2008) who found that seroprevalence among sheep was 0.00\%. In the same vein, Bekele et al. (2011) and Ebid and Salib (2020) respectively reported similar estimates of $1.2 \%$ and $0.48 \%$, which were lower than the estimated rates of $20 \%$ and $15 \%$ respectively reported in the studies conducted by Abdel-Razik et al. (2007) and Hegazy et al. (2009). Similar to the obtained results of the current study concerning goats, (Samaha, 2008) estimated seroprevalence rates as $0.00 \%$, which was almost near to the reported rates of $1.3 \%$ and $1.9 \%$ mentioned by Tekleye et al. (1989) and Megersa et al. (2011), respectively. However, the calculated percentages were lower than the ones recorded by Ahmed et al. (2010), Kaoud et al. (2010), Montiel et al. (2013), and Musallam et al. (2015) in the related studies ( i.e., $31 \%, 18.88 \%, 34.3 \%$, $38 \%$, respectively). Accordingly, none of the farm animals were infected with brucellosis in the New Valley Governorate, which can be due to very strict measures on animal importation from outside the governorate. Natural and geographical features of the governorate are not considered an appropriate environment for Brucella owing to low humidity, very high temperature, and rare showers. Furthermore, most animal keepers in the country avoid locating different types of animals together in the same place.

The RBT is an ideal screening test for human brucellosis since it is a simple, rapid, and highly sensitive test for individual diagnoses (Teng et al., 2017). In the present study, the overall prevalence of human brucellosis by RBT was $23.9 \%$ (Table 4), which was similar to the obtained results of studies conducted by Yohannes et al. (2012), El-Diasty et al. (2016), and Diab et al. (2018), in which they estimated the rates as $26.6 \%, 21 \%$, and $24.3 \%$, respectively. These estimates were higher than those (i.e., 1.25\%, 13.1\%, 5.6\%, 9.44\%, 6.3\%) recorded by Elmonir et al. (2016), Salem et al. (2016), Awah-Ndukum et al. (2018), Abdelbaset et al. (2018) and Ramadan et al. (2019), respectively. On contrary, the reported ratios were lower than those calculated in studies conducted by Hussien et al. (2007) and Hassanain and Ahmed, (2012), which were $32.3 \%$ and $83.3 \%$, respectively. This dissimilarity in the prevalence of human brucellosis in the current work and others may be due to different geographic locations, age range and gender distribution, variation in occupational contact, and the type of implemented tests (Alton et al., 1988). The presented data in table 6 and Figure 1 indicated that the risk factor of age can lead to significant differences. The higher percentage of infection was observed among individuals aged above 40 (28.57\%). This finding was also supported by several studies, including those performed by Abdelbaset et al. (2018), Tumwine et al. (2015), and Saddique et al. (2019). In contrast, some other researchers (Nagati and Hassan, 2016; Salem et al., 2016;Tsegay et al., 2017; Saraya, 2017) reported that the highest infection rate of brucellosis was observed among individuals with the age range of 20-44 years, compared to the younger or older ones.

With regard to the prevalence of human brucellosis and locality, it was found that there was a significant association between the seroprevalence of brucellosis among humans and locality in New Valley Governorate (table 6 and figure 2). This finding was in line with the obtained results of a study by Nossair and Haggag, (2016), where there was a significant association between the seroprevalence of brucellosis among humans and locality ( $p<0.0001)$. Addressing the effect of gender on human brucellosis prevalence, it was observed that the seroprevalence of brucellosis was higher in males $(26.11 \%)$ than females $(22.5 \%)$ although gender had no significant effect on the prevalence of brucellosis (table 6 and figure 3). Similarly, (El Mabrouk, 2013) found a non-significant association between the prevalence of brucellosis and gender. Analysis of the effect of weather on brucellosis showed that weather conditions had a significant effect on brucellosis with the highest infection rate during related to the seasons with hot weather (table 6 and figure 4) which was confirmed by Lolika et al. (2017) and Ayoub et al. (2019). However, (Diab et al., 2018) noticed that the highest infection rate occurred during the winter season (43.1\%). As can be seen in figure 5, contact with animals have a significant effect on brucellosis with the highest infection rate in individuals at close contact with animals (28.4\%) than those with no contact with animals (18.8\%) supported by Diab et al. (2018). Figure 6 illustrated that the seroprevalence of brucellosis was higher in the raw milk consumers group $(25.5 \%)$ than non-milk consumers groups 
(22.4\%) with a non-significant effect on dairy products, which was also confirmed by George et al. (2014). According to figure 7, the highest seroprevalence was recorded in the abattoir workers followed by farmers, animal keepers, and housewives indicating a significant association between different occupations and the prevalence of human brucellosis. This result agreed with those obtained by Nossair and Haggag, (2016) and Ramadan et al. (2019), who found that abattoir workers had the highest percentage followed by farmers, householders, and milker's housewives.

The obtained results of table 7 showed that the sensitivity rates of RBT and ELISA in terms of the diagnosis of brucellosis in human were $76.92 \%$ and $100 \%$, respectively, while the specificity of the two tests were $100 \%$ and $96.88 \%$, respectively, as compared with that of the CFT as a gold standard. These results were nearly similar to those reported by Shaaban et al. (2018), who found that the specificity of RBT was 97.77\%, and (Rojas and Alonso, 1998), who found that the sensitivity and the specificity rates of $78.1 \%$ and $100 \%$ for RBT as well as $100 \%$ and $100 \%$ for ELISA, respectively.

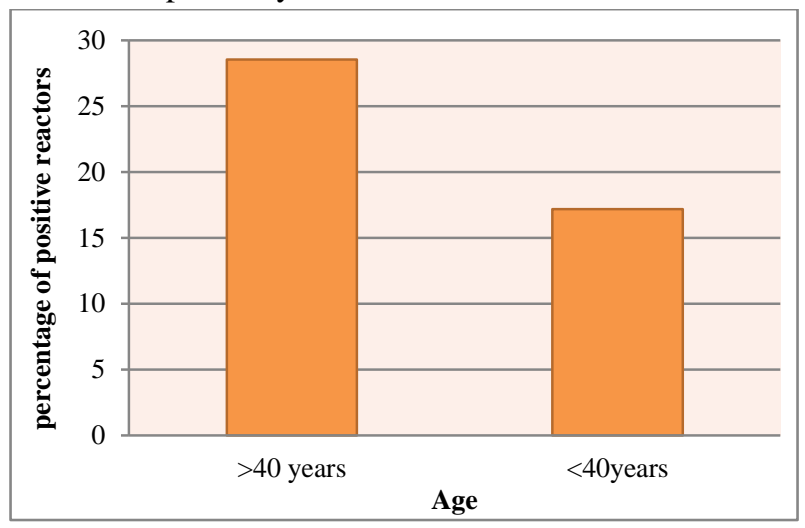

Figure 1. Seroprevalence of brucellosis in human beings using RBT regarding age groups in New Valley Governorate, Egypt

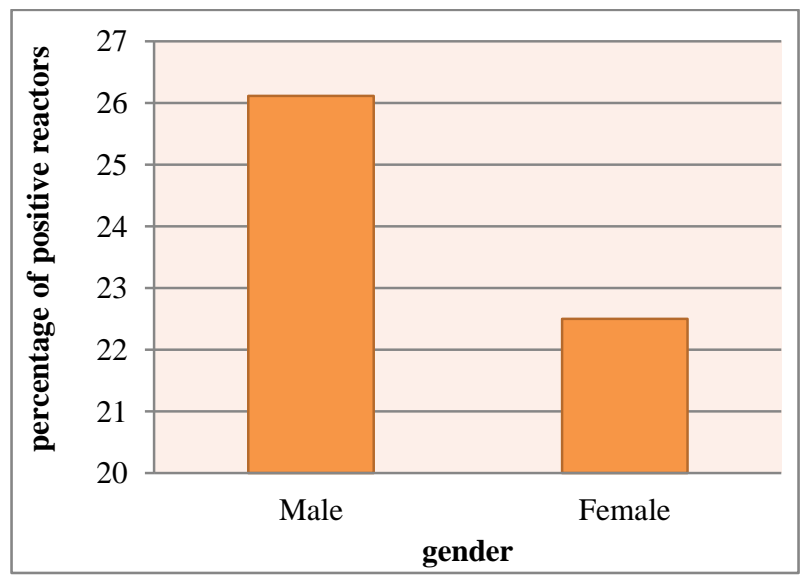

Figure 3. Seroprevalence of brucellosis in human beings using RBT in relation to gender in New Valley Governorate, Egypt

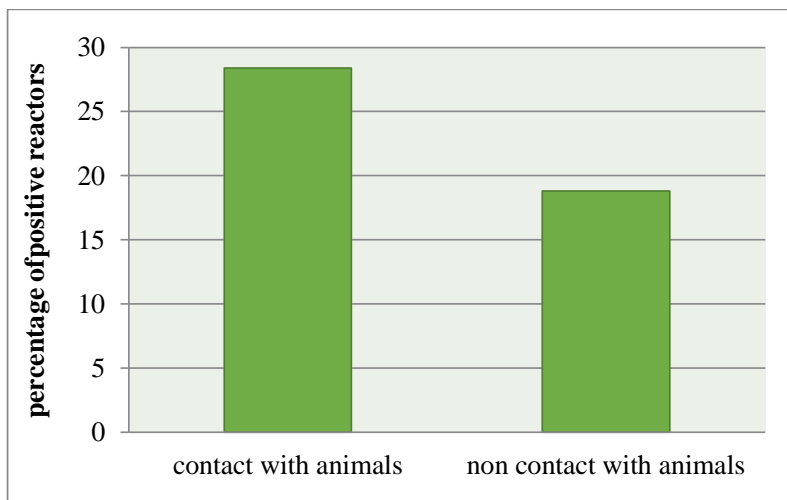

Figure 5. Prevalence of brucellosis in humans regarding contact with different animals in in New Valley Governorate, Egypt

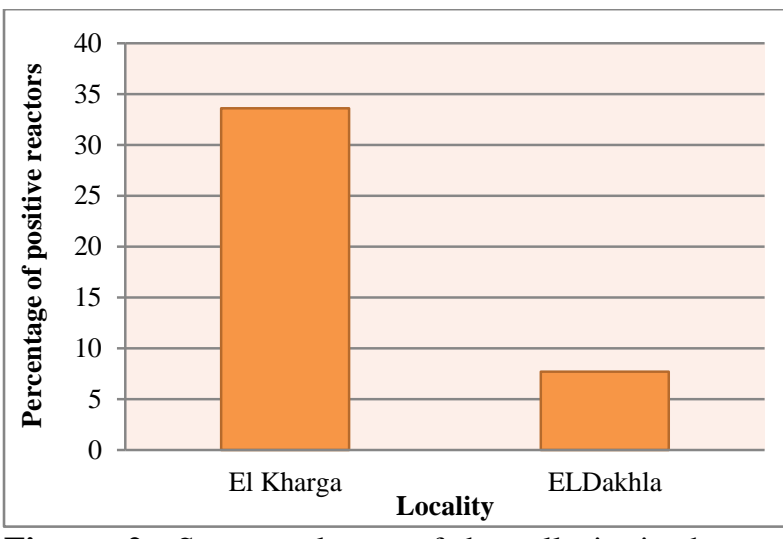

Figure 2. Seroprevalence of brucellosis in human beings using RBT regarding locality in New Valley Governorate,

Egypt

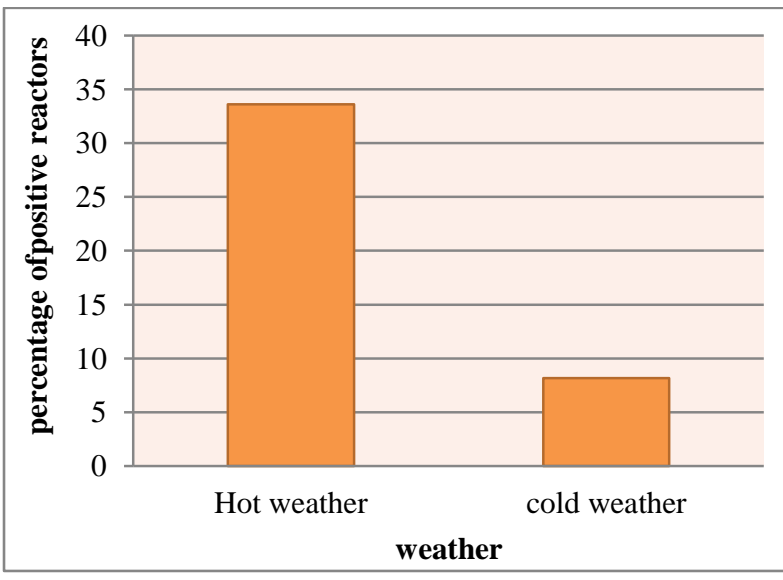

Figure 4. Seroprevalence of brucellosis in human beings using RBT regarding weather in New Valley Governorate,

Egypt

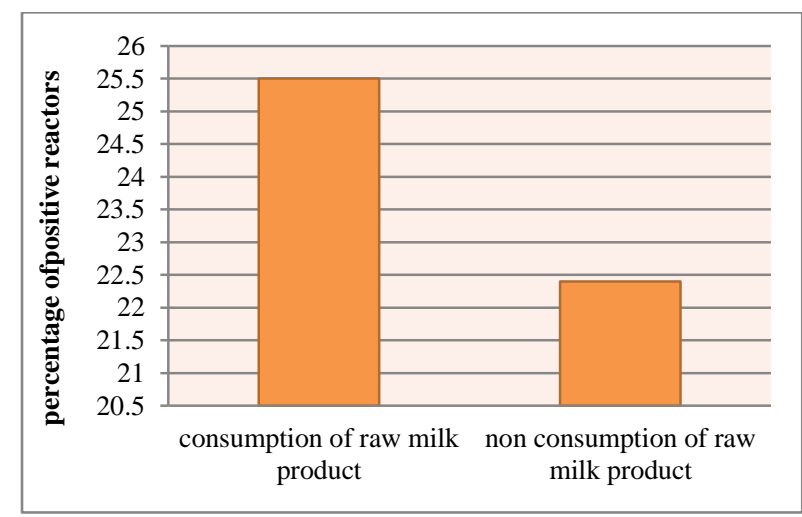

Figure 6. Prevalence of brucellosis in humans regarding consumption of raw milk product in in New Valley Governorate, Egypt 


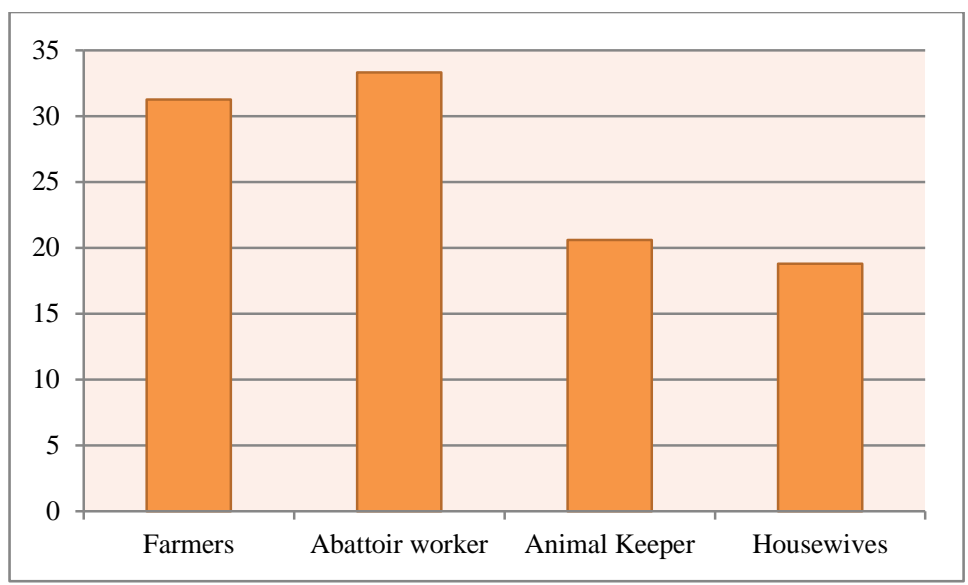

Figure 7. Prevalence of brucellosis in humans regarding occupation in New Valley Governorate, Egypt

\section{CONCLUSION}

According to the setting and the obtained results of the current study (the first report for this area), it can be concluded that there was no reported case of brucellosis among the farm animals of New Valley Governorate. Concerning humans, brucellosis is an alarming problem in New Valley Governorate and threatens the human population through the direct and indirect transmission. There was no relationship between the recorded high prevalence of brucellosis in humans residing in New Valley Governorate and the livestock infection. The highest infection rate was recorded in Abattoir workers and Farmers than in any other occupations. Further investigation is required for other possible sources of infection. A combination of different serological tests is the best method to obtain a well-thought diagnosis of brucellosis.

\section{DECLARATIONS}

\section{Acknowledgments}

This study was supported by the University of Sadat City and Veterinary Serum and Vaccine Research Institute (VSVRI) in Abbassia, Cairo, Egypt. The authors would also like to thank our colleagues Ghada A. Haddad and Yasser Elnaker.

\section{Competing interests}

All authors have no conflict of interest.

\section{Author's contributions}

Nermine A. Hassan, Ahmed M Bayoumi, Mohamed S. Diab, and Sherif Abd Allah Zidan conceived and designed the experiments. Nermine A. Hassan, Haitham Eladli and Mohamed S. Diab performed the experiments. Nermine A. Hassan, Haitham Eladli, and Sherif Abd Allah Zidan contributed reagents/ materials/ analysis tools. Nermine A. Hassan and Sherif Abd Allah Zidan wrote the paper

\section{REFERENCES}

Abdel-Razik K, Desouky H, and Ahmed W (2007). Investigations on brucellosis in Egyptian baladi does with emphasis on evaluation of diagnostic techniques. Pakistan Journal Biological Sciences, 10: 342-348. DOI: https://doi: 10.3923/pjbs.2007.342.348.

Abdelbaset AE, Abushahba MFN, Hamed MI, and Rawy MS (2018). Serodiagnosis of brucellosis in sheep and humans in Assiut and El-minya governorates, Egypt. International Journal of Veterinary Science and Medicine., 6 (Suppl): S63-S67. DOI: https://doi.org/10.1016/j.ijvsm.2018.01.007.

Acha PN, and Szyfres B (2003). Zoonoses and communicable diseases common to man and animals: Pan American Health Organization, I: 41-51. Available at:https://www.paho.org/hq/dmdocuments/2012/Acha-Zoonoses-Eng.pdf

Afifi S, Earhart K, Azab MA, Youssef FG, El Sakka H, Wasfy M, Mansour H, El Oun S, Rakha M, and Mahoney F (2005). Hospital-based surveillance for acute febrile illness in Egypt: A focus on community-acquired bloodstream infections. The American journal of tropical medicine and hygiene, 73 (2): 392-399. DOI: https://doi.org/10.4269/ajtmh.2005.73.392.

Ahmed M, Elmeshri S, Abuzweda A, Blauo M, Abouzeed Y, Ibrahim A, Salem H, Alzwam F, Abid S, and Elfahem A (2010). Seroprevalence of brucellosis in animals and human populations in the western mountains region in Libya, december 2006-january 2008. Eurosurveillance, 15 (30): 19625. Available at: https://www.eurosurveillance.org/content/10.2807/ese.15.30.19625-en.

Alton G, Jones L, Angus R, and Verger J (1988). Techniques for the brucellosis laboratory, institut national de la recherche agronomique, Paris. Verger Versailles Cedex: INRA Publications., 192: 195.

Anka MS, Hassan L, Adzhar A, Khairani-Bejo S, Mohamad RB, and Zainal MA (2013). Bovine brucellosis trends in Malaysia between 2000 and 2008. BMC veterinary research, 9 (1): 230. DOI: https://dx.doi.org/10.1186/1746-6148-9-230. 
Aparicio ED (2013). Epidemiology of brucellosis in domestic animals caused by brucella melitensis, brucella suis and brucella abortus. Revue scientifique et technique, 32(1): 53-60. DOI: https://doi.org/10.20506/RST.32.1.2187.

Ashraf A, El Hofy F, Ramadan KM, and Harb FE (2014). Comparative evaluation of standard serological tests for diagnosis of ovine brucellosis. Banha veterinary medical journal, 2: 423-429. Available at: https://www.bvmj.bu.edu.eg/issues/27-2/42.pdf.

Awah-Ndukum J, Mouiche MMM, Kouonmo-Ngnoyum L, Bayang HN, Manchang TK, Poueme RSN, Kouamo J, Ngu-Ngwa V, Assana E, and Feussom KJM (2018). Seroprevalence and risk factors of brucellosis among slaughtered indigenous cattle, abattoir personnel and pregnant women in Ngaoundéré, Cameroon. BMC infectious diseases,18(1): 611. DOI: https://dx.doi.org/10.1186\%2Fs12879-018-3522-X.

Ayoub M, Badran A, and Nosair M (2019). Raw milk as a vehicle of brucella infection for human in Behera province. Damanhour Journal of Veterinary Sciences, 1(2): 7-10. Available at: https://djvs.journals.ekb.eg/article_47989_9a2cabeed725c55b104eac9921974406.pdf.

Bekele M, Mohammed H, Tefera M, and Tolosa T (2011). Small ruminant brucellosis and community perception in Jijiga district, Somali regional state, eastern Ethiopia. Tropical animal health and production, 43 (4): 893-898. DOI: https://doi.org/10.1007/s11250-011-9781-9.

Cadmus SIB, Ijagbone IF, Oputa HE, Adesokan HK, and Stack JA (2006). Serological survey of brucellosis in livestock animals and workers in Ibadan, Nigeria. African Journal of Biomedical Research, 9 (3). DOI: https://doi.org/10.4314/ajbr.v9i3.48900.

Chisi SL, Marageni Y, Prebashni Naidoo P, Zulu NG, George W, Akol G, and Van Heerden H (2017). An evaluation of serological tests in the diagnosis of bovine brucellosis in naturally infected cattle in Kwazulu-Natal province in South Africa. Journal of the South African veterinary assoscition, 88: 1381. DOI: https://dx.doi.org/10.4102\%2Fjsava.v88i0.1381.

Corbel MJ (2006). Brucellosis in humans and animals: World Health Organization. Available at: https://www.who.int/csr/resources/publications/Brucellosis.pdf

Diab MS, Elnaker YF, Ibrahim NA, Sedeek EK, and Zidan SA (2018). Seroprevalence and associated risk factors of brucellosis in sheep and human in four regions in Matrouh governorate, Egypt. World's Veterinary Journal, 8 (4): 65-72. Available at: https://wvj.science-line.com/vol-8-no-4-dec2018.html.

Ebid MEM A, and Salib F (2020). Seroprevalence of brucellosis in sheep and goats in the Arabian Gulf region. Veterinary World, 13(8): 1495-1509. DOI: https://www.doi.org/10.14202/vetworld.2020.1495-1509.

El-Diasty MM, Ahmed HA, Sayour AE, El Hofy FI, Tahoun ABMB, and Shafik SM (2016). Seroprevalence of brucella spp. In cattle, molecular characterization in milk, and the analysis of associated risk factors with seroprevalence in humans, Egypt. Vector-Borne and Zoonotic Diseases, 16(12): 758-764. DOI: https://doi.org/10.1089/vbz.2016.1985.

El Mabrouk KS (2013). Serological investigation of some bacterial zoonotic diseases transmitted through ruminants MVSc, Thesis (Zoonoses), Faculty of Veterinary Medicine Alexandria University.

Elmonir W, Hegazy YM, Abdel-Hamid NH, and Elbauomy EM (2016). Brucellosis at the human-animal interface in Kafr-Elsheikh governorate, Egypt. Alexandria Journal for Veterinary Sciences, 50(1): 1-7. DOI: https://doi.org/10.5455/ajvs.229337.

Eltholth MM, Abd El- Wahab EW, Hegazy YM and El-Tras WF (2015). Assessing impacts and costs of brucellosis control programme in an endemic area of the Nile Delta, Egypt. World's Veterinary Journal, 5(4):74-81 Available at http://wvj.scienceline.com/attachments/article/32/World's\%20Vet.\%20J.\%205(4)\%2074-81,\%20December\%2025,\%202015.pdf.

Eltholth MM, Hegazy YM, El-Tras WF, Bruce M, and Rushton J (2017). Temporal analysis and costs of ruminant brucellosis control programme in Egypt between 1999 and 2011. Transboundary and emerging diseases, 64 (4): 1191-1199. DOI: https://doi.org/10.1111/tbed.12491.

Fatima S, Khan I, Nasir A, Younus M, Saqib M, Melzer F, Neubauer H and El-Adawy H (2016). Serological, molecular detection and potential risk factors associated with camel brucellosis in Pakistan. Tropical animal health and production,48(8):1711-1718. DOI: https://doi.org/10.1007/s11250-016-1148-9.

George N, Edward S, John O, Patrice G, Eric E, and Alban B (2014). Brucella sero-prevalence and modifiable risk factors among predisposed cattle keepers and consumers of un-pasteurized milk in Mbarara and Kampala districts, Uganda. African health sciences, 14(4):790-796. DOI: https://doi.org/10.4314/ahs.v14i4.3.

Godfroid J (2017). Brucellosis in livestock and wildlife: Zoonotic diseases without pandemic potential in need of innovative one health approaches. Archives of Public Health, 75(1): 34. DOI: https://doi.org/10.1186/s13690-017-0207-7.

Hassanain N, and Ahmed W (2012). Sero-prevalence of brucellosis in Egypt with emphasis on potential risk factors. World Journal of Medical Sciences,7(2):81-86. Available at: https://www.researchgate.net/publication/287567526.

Hegazy YM, Ridler AL, and Guitian FJ (2009). Assessment and simulation of the implementation of brucellosis control programme in an endemic area of the Middle east. Epidemiology and Infection, 137 (10): 1436-1448. DOI: https://doi.org/10.1017/S0950268809002301.

Hussien A, Oraby N, Ismail A, Elias A, and Abdel-Kader H (2007). The use of Elisa for diagnosis and epidemiology of brucella infection in humans in Assiut governorate. Veterinary Medical Journal-Giza, 55: 867-877. Available at: https://vlibrary.emro.who.int/imemr/the-use-of-elisa-fordiagnosis-and-epidemiology.

Kaoud H, Zaki M, El-Dahshan A, and Nasr A (2010). Epidemiology of brucellosis among farm animals. Nature and Science, 8(5):190-197. Available at: https://citeseerx.ist.psu.edu/viewdoc/download?doi=10.1.1.465.3723\&rep=rep1\&type=pdf.

Lolika PO, Mushayabasa S, Bhunu CP, Modnak C, and Wang J (2017). Modeling and analyzing the effects of seasonality on brucellosis infection. Chaos, Solitons and Fractals, 104: 338-349. DOI: https://doi.org/10.1016/j.chaos.2017.08.027.

Mathew C, Stokstad M, Johansen TB, Klevar S, Mdegela RH, Mwamengele G, Michel P, Escobar L, Fretin D, and Godfroid J (2015). First isolation, identification, phenotypic and genotypic characterization of brucella abortus biovar 3 from dairy cattle in Tanzania. BMC veterinary research, 11 (1): 156. DOI: https://doi.org/10.1186/s12917-015-0476-8.

Megersa B, Biffa D, Niguse F, Rufael T, Asmare K, and Skjerve E (2011). Cattle brucellosis in traditional livestock husbandry practice in southern and eastern Ethiopia, and its zoonotic implication. Acta Veterinaria Scandinavica, 53 (1): $24 . \quad$ Available at: https://www.ncbi.nlm.nih.gov/pubmed/21473760.

Montiel DO, Frankena K, Udo H, Baer NMK, and Van der Zijpp A (2013). Prevalence and risk factors for brucellosis in goats in areas of Mexico with and without brucellosis control campaign. Tropical animal health and production, 45 (6): 1383-1389. https://doi.org/10.1007/s11250-013-0375-6.

Musallam I, Abo-Shehada M, Omar M, and Guitian J (2015). Cross-sectional study of brucellosis in Jordan: Prevalence, risk factors and spatial distribution in small ruminants and cattle. Preventive veterinary medicine, 118 (4): 387-396. DOI: https://doi.org/10.1016/j.prevetmed.2014.12.020.

Nagati S and Hassan SK (2016). Diagnosis of brucella infection in sheep and goat and evaluation of the associated practices in animal contacts American Journal of Infectious Diseases and Microbiology, 4(5): 95-101. DOI: https://doi.org/10.12691/ajidm-4-5-1.

Nagi SDG (2003). Brucellosis in Yemen and Sudan seroprevalence, causative agent and evaluation of different methods of diagnosis Ph. D. thesis, University of Khartoum, Sudan. 
Nossair MA, and Haggag YN (2016). Using competitive Elisa for accurate diagnosis of brucellosis in humans in Alexandria province with emphasis on the disease epidemiology. Alexandria Journal for Veterinary Sciences, 51 (2): 296-302. DOI: https://doi.org/10.5455/ajvs.239565.

Pappas G, and Memish Z (2007). Brucellosis in the Middle east: A persistent medical, socioeconomic and political issue. Journal of Chemotherapy,19(3):243-248. DOI: https://doi.org/10.1179/joc.2007.19.3.243.

Ramadan ES, Nassar NR, Ibrahim IG, and Zayed AF (2019). Epidemiological and zoonotic surveillance of brucellosis in Beni-Suef governorate. Alexandria Journal for Veterinary Sciences, 61 (1): 22-31. DOI: https://doi.org/10.5455/ajvs.39738.

Refai M (2002). Incidence and control of brucellosis in the near east region. Veterinary Microbiology, 90: 81-110. DOI: https://doi.org/10.1016/S0378$1135(02) 00248-1$.

Rojas X, and Alonso O (1998). Elisa for the diagnosis and epidemiology of brucella abortus infection in cattle in Chile. Joint FAO/IAEA Division of in Food and Agriculture, Vienna, pp. 77-81. Available at:https://inis.iaea.org/collection/NCLCollectionStore/_Public/29/067/29067678.pdf

Saddique A, Ali S, Akhter S, Khan I, Neubauer H, Melzer F, Khan AU, Azam A, and El-Adawy H (2019). Acute febrile illness caused by brucella abortus infection in humans in Pakistan. International journal of environmental research and public health, 16(21): 4071. DOI: https://doi.org/10.3390/ijerph16214071.

Salem L, Khalifa NO, and Moustafa SM (2016). Sero-diagnosis of brucellosis in Gharbiya governorate, Egypt. Banha veterinary medical journal,31(1):10-16. DOI: https://doi.org/10.21608/BVMJ.2016.3121 1 .

Samaha HAH AM (2008). Viability of brucella melitensis biovar 3, in milk and some dairy products. Egyptian Journal of Medical Microbiology, 17(2): 1916-1918. DOI: https://doi.org/10.3201/eid1412.071452.

Saraya MA (2017). Acute brucellosis: Presentation and complications in adults. Afro-Egyptian Journal of Infectious and Endemic Diseases, 7(4):186191. DOI: https://doi.org/10.21608/aeji.2017.17802.

Shaaban SI, Ayoub MA, Ghorbal SH, and Nossair M (2018). Calves as a reservoir of some diarrheagenic agents for human contacts in El-Behira province. Alexandria Journal for Veterinary Sciences, 56 (2): 48-53. DOI: https://doi.org/10.1186/s12879-017-2208-0.

Tekleye BKO, Mugurewa M, Sholtens RG, and Tamirat Y (1989). The prevalence of brucellosis in indigenous cattle in central Ethiopia. Bulletin of Animal Health and Production in Africa., 37 (1): 97-98. Available at: https://hdl.handle.net/10568/29305

Teng YH, Teng JJ, Chao S, Chao H, and Waghela SD (2017). Comparison of the rose bengal plate and the complement fixation tests with the tube agglutination test for diagnosis of human brucellosis. Open Journal of Clinical Diagnostics, 7:73. DOI: https://doi.org/10.20506/rst.31.3.2175.

Tsegay A, Tuli G, Kassa T, and Kebede N (2017). Seroprevalence and risk factors of brucellosis in abattoir workers at Debre Zeit and modjo export abattoir, central Ethiopia. BMC infectious diseases, 17 (1): 101. DOI: https://doi.org/10.1186/s12879-017-2208-0.

Tumwine G, Matovu E, Kabasa JD, Owiny DO, and Majalija S (2015). Human brucellosis: Sero-prevalence and associated risk factors in agro-pastoral communities of Kiboga district, central Uganda. BMC public health, 15 (1): 900. DOI: https://doi.org/10.1186/s12889-015-2242-z.

Wareth GH A, Refai M, Melzer F, Roesler U, and Neubauer H (2014). Animal brucellosis in Egypt. Journal of Infection in Developing Countries, 8 (11): 1365-1137. DOI: https://doi.org/10.3855/jidc.4872.

Yohannes M Gill J P, Ghatak S, Singh D K and Tolosa T (2012). Comparative evaluation of the rose bengal plate test, standard tube agglutination test and complement fixation test for the diagnosis of human brucellosis. Revue scientifique et technique, 31(3): 979-984. DOI: https://doi.org/10.20506/rst.31.3.2175.

Young JS, Gormley E, and Wellington EM (2005). Molecular detection of mycobacterium bovis and mycobacterium bovis bcg (pasteur) in soil. Applied and environmental microbiology, 71 (4): 1946-1952. DOI: https://10.1128/AEM.71.4.1946-1952.2005.

Zakaria AM, Ahmed SF, and Motawae MS (2018). Seropositivity in animals and risk of occupational brucellosis among abattoirs personnel associated with poor work practices and absence of safety policy in Egypt. International journal of occupational and environmental health, 24 (1-2): 55-60. DOI: https://doi.org/10.1080/10773525.2018.1516839. 